\title{
Occurrence of Potential Bacterial Pathogens and Their Antimicrobial Susceptibility Patterns Isolated from Herbal Medicinal Products Sold in Different Markets of Gondar Town, Northwest Ethiopia
}

\author{
Abdela Yesuf, ${ }^{1}$ Yitayih Wondimeneh, ${ }^{2}$ Teklay Gebrecherkos, ${ }^{2}$ and Feleke Moges ${ }^{2}$ \\ ${ }^{1}$ Department of Medical Laboratory, Debark Hospital, P.O. Box 196, Debark, Ethiopia \\ ${ }^{2}$ School of Biomedical and Laboratory Sciences, College of Medicine and Health Sciences, University of Gondar, \\ P.O. Box 196, Gondar, Ethiopia \\ Correspondence should be addressed to Teklay Gebrecherkos; estiftg17@gmail.com
}

Received 3 November 2015; Accepted 8 February 2016

Academic Editor: Mariagrazia Perilli

Copyright (C) 2016 Abdela Yesuf et al. This is an open access article distributed under the Creative Commons Attribution License, which permits unrestricted use, distribution, and reproduction in any medium, provided the original work is properly cited.

\begin{abstract}
Background. The World Health Organization estimates that about $80 \%$ of the world's population uses herbal medicine to treat various illnesses as means of primary healthcare. However, during preparation, herbal plants may be exposed to contamination by potential pathogens, and this may lead to infections. The aim of this study was to determine bacterial contamination of herbal medicinal products and to assess the antibiotic susceptibility pattern of the isolated bacteria. Methods. A cross-sectional study was conducted from January 1 to May 25, 2013, at Gondar Town. A total of 55 samples used as oral, local, and intranasal routes of administration were collected from the herbalists. Results. In the present study the total aerobic bacterial count ranges from zero to $2.41 \times 10^{9} \mathrm{CFU} / \mathrm{g}$ with mean count of $1.99 \times 10^{8} \mathrm{CFU} / \mathrm{g}$ or $\mathrm{mL}$ while the total coliform count showed an average of $1.05 \times 10^{8} \mathrm{CFU} / \mathrm{g}$ or $\mathrm{mL}$ with a range of zero to $2.1 \times 10^{9} \mathrm{CFU} / \mathrm{g}$. The most common bacteria isolated were Bacillus spp. followed by Enterobacter spp., Shigella dysenteriae, and Salmonella spp. Multiple drug resistance was not uncommon and it was found that 125 (83.4\%) of the isolates were resistant to two or more antibiotics. Conclusion. Herbal medicinal preparations were highly contaminated with pathogenic microorganisms with high microbial load. Most of the isolates have multiple drug resistance. Using those contaminated herbal medicines may lead to infection of other health related risks. Therefore, this warrants urgent training of herbalists and management scale-up for quality and safety of medicinal plants.
\end{abstract}

\section{Introduction}

The use of herbal medicine is generally increasing worldwide [1]. In many developed countries, $70-80 \%$ of the population still depends upon herbal drugs for their health care [1-3]. Similarly in developing countries such as Africa, up to $80 \%$ of the population relies on herbal medicine as a major source of therapy $[1,3,4]$.

Although the World Health Organization (WHO) has advocated the integration of herbal medicinal products (HMPs) into the primary health care system of developing countries, safety issues related to herbal drug preparations continue to be ignored by the herbalist [5]. So the safety of herbal products became a major concern in public health [6]. This is because microorganisms of various kinds are normally adherent to leaves, stem, flowers, seeds, and roots from which herbal medicine can be prepared and potential pathogens may also be introduced during harvesting, handling [6,7], open-air drying, preserving, manufacturing [6], and use of contaminated materials for storage $[7,8]$. According to some reports, the consumers may possibly fall into illness because of taking herbs incriminated with pathogenic microorganisms [8] and sometimes the presence of antibiotic resistant microbial isolates in the HMPs will lead to transfer of antibiotic resistance strains to consumers [9]. Different studies that have been performed on herbal medicinal products 
revealed the presence of bacterial pathogens with multiple drug resistance [10].

In Ethiopia, due to the cultural acceptability of healers, the relatively low cost of traditional medicine, and limited access to modern health facilities [11] up to $80 \%$ of the population uses traditional medicine [11, 12]. Ethiopia has high diversity of plant species most of which are used in the preparation of herbal medicinal products and it is one of the six African countries where about $60 \%$ of the plants are said to be indigenous with their healing potential [13]. The growing and unhygienic use of herbal medicinal products has become a major concern in public health [6]. However, in Ethiopia particularly in the study area, there is no sufficient data which addresses the bacteriological quality of herbal medicinal products. Hence the aim of this study was to assess the occurrence of potential bacterial pathogens and their antimicrobial susceptibility patterns isolated from herbal medicinal products sold in different markets of Gondar Town, Northwest Ethiopia.

\section{Materials and Methods}

2.1. Study Area, Design, and Period. A cross-sectional study was conducted from January 1 to May 25, 2013, at Gondar Town. Gondar is located in the Northwestern part of Ethiopia, about $740 \mathrm{~km}$ far from Addis Ababa, the capital city of Ethiopia. The town has an estimated area of 41.27 square $\mathrm{Km}$, with altitude of 2200 meters above sea level, having a total population of more than 252,537 [14].

2.2. Source of Population. All types of herbal medicinal products with oral, local, and intranasal route of administration have been sold at different markets of Gondar Town.

2.3. Study Subjects. All types of herbal medicinal products prepared by the 20 herbalists of Gondar Town who have been enrolled in association of traditional medicine named "ZeriaBiruk Association of Traditional Medical Practitioner" were the study subjects.

2.4. Sample Size and Sampling Technique. In the present study, a total of 55 (13 liquid and 42 solid) samples were taken from all herbalists. From each herbalist herbal medicinal products prepared for oral, local (body lotion), and inhalation use were considered. All orally, locally, and intranasal consumed powder form preparations and all liquid samples were purchased and included in the study. Route of administration of the herbal traditional medicine can be mainly in oral, body lotion, and inhalation type and the present study gives more attention to those herbal medicinal products.

Inclusion Criteria. Those powder and liquid preparations of herbal medicinal products administered orally, locally, and intranasally without further processing were included in the study.

Exclusion Criteria. Those powder form herbal medicinal products with further processing and other routes of administration were excluded in the study.
2.5. Data Collection, Handling, and Transporting of Specimens. A total of 55 different herbal (42 powder and 13 liquid) preparations were purchased randomly from identified herbalists in Gondar Town. Using aseptic techniques, from each liquid herbal preparation about $5 \mathrm{~mL}$ of sample was collected in a sterile screw-capped test tube and about 3 to $10 \mathrm{~g}$ of solid (powder) sample was also collected by using labeled wide-necked test tubes. All the samples were transported to the Medical Microbiology Laboratory of Gondar University Hospital with cold box within one hour of collection. Liquid specimens were refrigerated at $4^{\circ} \mathrm{C}$ till processing.

2.6. Isolation and Identification of Bacteria. Liquid samples were homogenized by mixing vigorously and transferred $1 \mathrm{~mL}$ sample to $9 \mathrm{~mL}$ sterile saline. At the same time, the liquid solution was prepared by mixing 1-gram powder with $9 \mathrm{~mL}$ of tryptone soy broth as a stock solution and then serial dilution was made to get appropriate dilution. All microbiological analyses were carried out in triplicate according to the standard [15-17]. By using a calibrated micropipette, $100 \mu \mathrm{L}$ volume of $10^{-3}, 10^{-5}$, and $10^{-7}$ was measured and dispensed by glass rod spreader to standard plate count and violet red bile agar media. Liquid preparations were also cultured on blood agar, MacConkey agar, and Salmonella Shigella agars and then incubated at $35-37^{\circ} \mathrm{C}$ for 18 to 24 hours.

At the end of the incubation period, the colonies on standard plate count media and violet red bile agar media were enumerated by using surface plate agar method using colony counter for total aerobic count and total coliform bacteria count, respectively. By multiplying the average number of colonies with dilution factor, it was calculated and reported as a colony forming unit per gram (CFU/g) of sample [1619]. The obtained CFU/g from 1-gram sample was compared with WHO standard $[5,20]$. Pure isolate of bacterial pathogen was preliminarily characterized by colony morphology and gram stain [19]. Bacterial identification was made using biochemical tests, namely, indole, citrate, oxidase, $\mathrm{H}_{2} \mathrm{~S}$ production, lysine decarboxylase, lactose fermentation, urea hydrolysis, gas production catalase, the coagulase, mannitol fermentation, and novobiocin susceptibility test. A standard biochemical procedure was also used for full identification of gram positive and gram negative bacteria [21].

2.7. Antimicrobial Susceptibility Testing. The antibiotic susceptibility test was performed by using disc diffusion method recommended by the Clinical and Laboratory Standards Institute (CLSI) guidelines [22] on Mueller-Hinton agar plate (Oxoid Ltd., Basingstoke, Hampshire, UK). The antibiotic discs and their concentration were amoxicillin (AML, $10 \mu \mathrm{g}$ ), chloramphenicol $(\mathrm{C}, 10 \mu \mathrm{g})$, cloxacillin (CXL, $5 \mu \mathrm{g}$ ), cotrimoxazole (SXT, $50 \mu \mathrm{g}$ ), ampicillin (AMP, $10 \mu \mathrm{g}$ ), ceftriaxone (CRO, $30 \mu \mathrm{g})$, gentamicin $(\mathrm{CN}, 10 \mu \mathrm{g})$, penicillin (PEN, $5 \mu \mathrm{g})$, nitrofurantoin (F, $300 \mu \mathrm{g})$, norfloxacin (N), and erythromycin $(\mathrm{E}, 5 \mu \mathrm{g})$. The inoculum was standardized by transferring pure colonies of the test organism into $5 \mathrm{~mL}$ of tryptone soy broth. The broth then incubates for three hours at $35-37^{\circ} \mathrm{C}$ to allow the growth of test organism and their inoculums sizes were compared with the turbidity of $0.5 \mathrm{McF}$ arland standard [10]. A sterile cotton swab was dipped into the suspension 
and excess suspension was removed by gentle rotation of the swab against the surface of the tube. Before placing the antimicrobial disc, the swab with the bacterial suspension was distributed evenly over the entire surface of Mueller-Hinton plates [10]. The plates were incubated at $37^{\circ} \mathrm{C}$ for $18-24$ hours. The diameter of the zone of inhibition was measured and interpreted using standard chart as sensitive, intermediate, and resistant [22]. The reference strains used as control were Escherichia coli (ATCC 25922) and Staphylococcus aureus (ATCC 25923).

2.8. Data Analysis. Data was checked for completeness, cleaned manually, entered, and analyzed using SPSS version 20 statistical package. Analysis was made using frequency tables. Pearson's test and odds ratio with 95\% CI were used for measures of association and $P$ value less than 0.05 was considered as statistically significant.

2.9. Ethical Considerations. This research project was conducted after obtaining institutional ethical clearance from School of Biomedical and Laboratory Sciences Ethical Committee. A supporting letter was obtained from Zonal Health Bureau and the chairman of the Association for Herbal Medicinal Plants. Informed consent was also obtained from each study participant. All the information obtained from the study was kept confidential.

\section{Results}

3.1. Sociodemographic Characteristics. Among the total of 22 herbalists, 20 (16 males and 4 females) of them were enrolled during the study while the other 2 (both males) refused to participate in the study. The mean age of the herbalists was 41.6 years with minimum and maximum age of 27 and 70 years, respectively. Of the study participants $7 / 20(35 \%)$ of them were illiterate and 1/20 (5\%) of them can only read and write but the rest 12/20 (60\%) of the herbalists were literate. $16 / 20(80 \%)$ of the herbalists were Orthodox and 4/20 (20\%) of them were Muslims. Regarding their experience, 13 (65\%) of the herbalists have more than 20 years, $2(10 \%)$ have $16-$ 20 years, 4 have (20\%) 6-10 years, and $1(5 \%)$ herbalist has 5 years.

3.2. Total Aerobic and Total Coliform Count. Among 55 samples analyzed, 5 samples ( 3 liquid and 2 powder) obtained from 5 different herbalists have no growth and 13 samples (9 powder and 4 liquid) obtained from 6 herbalists have zero coliform count. The total aerobic bacterial count of 55 samples was recorded with minimum count of zero (for samples of no growth) and maximum count of $2.41 \times$ $10^{9} \mathrm{CFU} / \mathrm{g}$ with mean count of $1.99 \times 10^{8} \mathrm{CFU} / \mathrm{g}$ and, except one $\left(6 \times 10^{4} \mathrm{CFU} / \mathrm{mL}\right.$, which was liquid), all the aerobic counts were beyond WHO tolerable limit. Total coliform count shows an average of $1.05 \times 10^{8} \mathrm{CFU} / \mathrm{g}$ or per $\mathrm{mL}$ with minimum of zero and maximum of $2.1 \times 10^{9} \mathrm{CFU} / \mathrm{g}$ (Table 1 ).

3.3. Correlation of Microbial Contaminants with Different Herbal Medicines. A total of 150 strains were isolated from the herbal preparations (Table 2). Of the isolates, 98/150
(65.3\%) were gram negatives and 52/150 (34.7\%) gram positives. 50 (90.9\%) contained pathogenic microorganisms or fecal indicators such as Escherichia coli, Staphylococcus aureus, and Pseudomonas aeruginosa. The organism most commonly isolated from the herbal medicines was Bacillus 31 (20.7\%) followed by Enterobacter cloacae 18 (12\%), Shigella dysenteriae 13 (8.7\%), Citrobacter spp. 12 (8\%), Providencia spp. 12 (8\%), Klebsiella pneumoniae 11 (7.3\%), Escherichia coli 10 (6.7\%), Staphylococcus aureus 10 (6.7\%), Staphylococcus epidermidis 5 (3.3\%), and others (Table 3 ).

3.4. Antimicrobial Susceptibility Patterns of the Isolates. Antimicrobial susceptibility patterns of gram negative and gram positive bacterial isolates from herbal medicinal products in Gondar Town are presented as shown in Tables 4(a) and 4(b). Majority of the isolates were resistant to ampicillin (131) (87.3\%), followed by amoxicillin clavulanic acid (95) (63.3\%), amoxicillin (92) (61.3\%), penicillin (30) (57.7\%), and nitrofurantoin (73) (48.7\%). However, the lowest rates of resistance were observed in gentamycin $(4.7 \%)$ followed by vancomycin (8) (5.3\%), erythromycin (9) (6.0\%), ciprofloxacin (11) (7.3\%), and norfloxacin (11) (7.3\%) (Table 5).

Multiple drug resistance bacteria were among the most isolated groups. The antimicrobial susceptibility-resistance pattern of the contaminating microorganisms revealed that 9/31 Bacillus species were resistant to 8 antimicrobial agents (ciprofloxacin, tetracycline, norfloxacin, augmentin, vancomycin, ceftriaxone, gentamicin, and cotrimoxazole) and it was also found that $131(87.3 \%)$ of the isolates were resistant to ampicillin, $95(63.3 \%)$ to amoxicillin clavulanic acid (augmentin), 92 (61.3\%) to amoxicillin, and 30 (57.7\%) to penicillin. Among bacterial isolates Pseudomonas aeruginosa were found to be resistant to at least 5 antibiotics tested while half of the isolates of Klebsiella ozaenae, Providencia spp., and Streptococcus pyogenes were resistant to 5 or more antibiotics tested (Table 6).

\section{Discussion}

Most of the medicinal plants are prepared in open environment and unhygienic condition which gradually lead to contamination of enteric pathogens having public health importance [20]. In the present study, from 55 herbal medicinal preparations, aerobic bacterial counts were obtained from 50 samples, of which only one has permutable limit of bacterial count according to WHO standard [20]. The other 49 samples were beyond WHO limit with minimum count of $4.6 \times 10^{5} \mathrm{CFU} / \mathrm{mL}$ and maximum of $2.41 \times 10^{9} \mathrm{CFU} / \mathrm{g}$ with mean count of $2.15 \times 10^{8} \mathrm{CFU} / \mathrm{g}$ or $\mathrm{mL}$. The total aerobic bacteria count in the present study is in agreement with the higher counts of aerobic bacteria found in herbal materials which have been studied by Ogunshe and Kolajo in Nigeria [23]. On the contrary, the present study has higher aerobic bacteria count than the study conducted from herbal medicinal preparation by Adeleye et al. at Lagos, Nigeria [24]. The reason why the total bacterial count in our study was higher may be due to the primitive ways of preparation of the plant products, poor environmental sanitation, and storage conditions. 


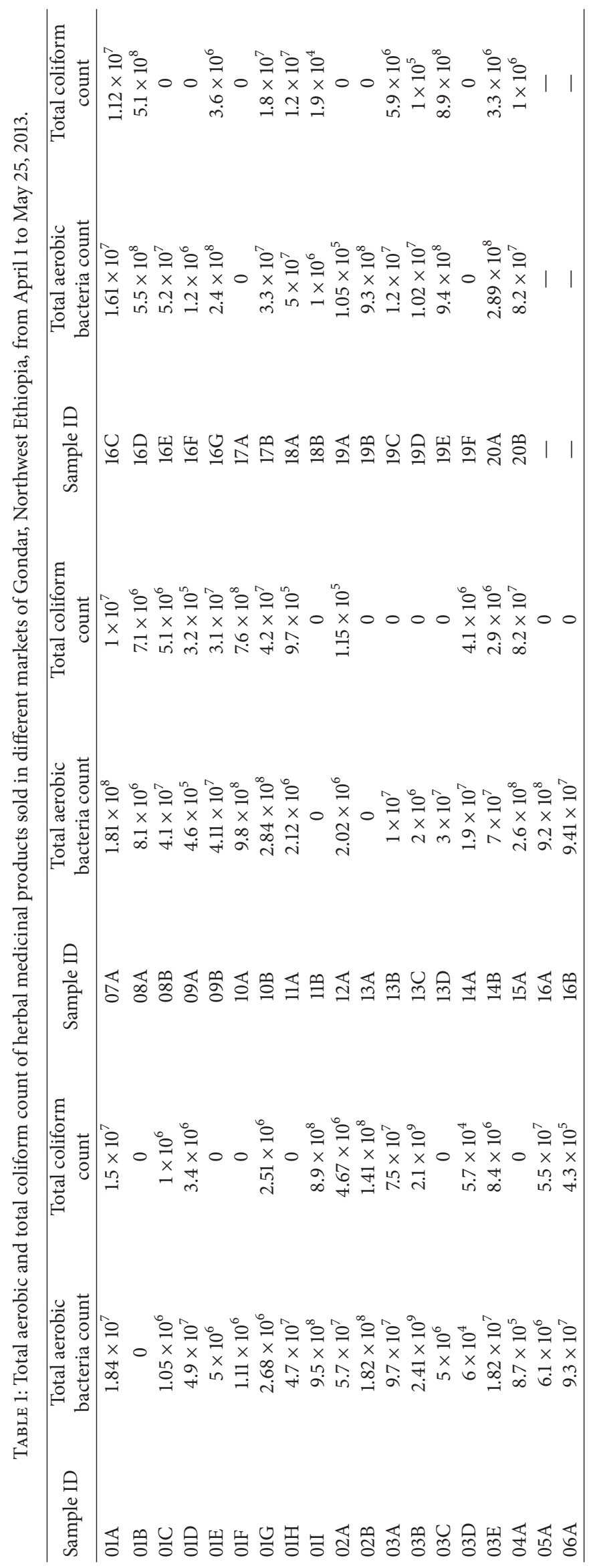




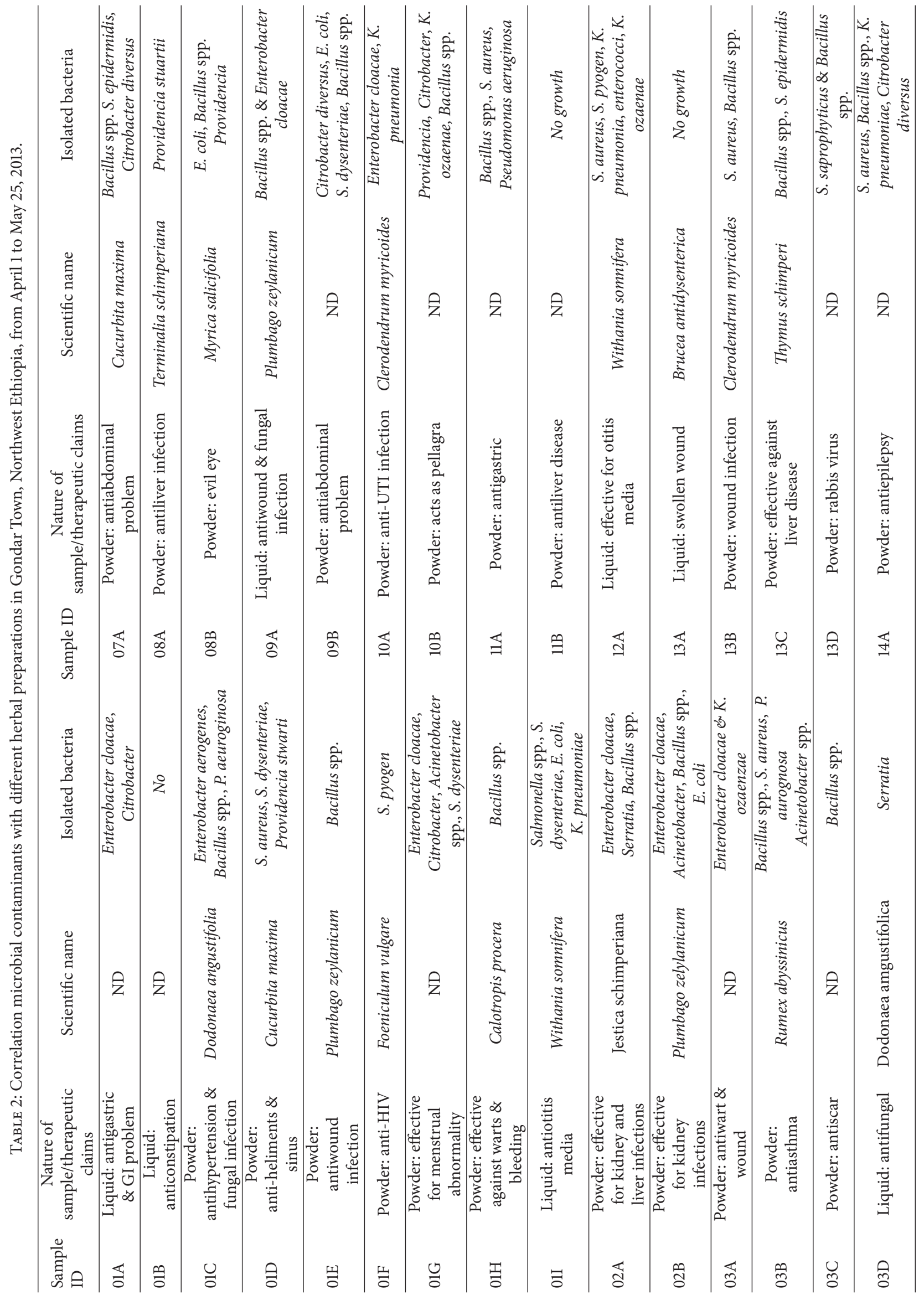




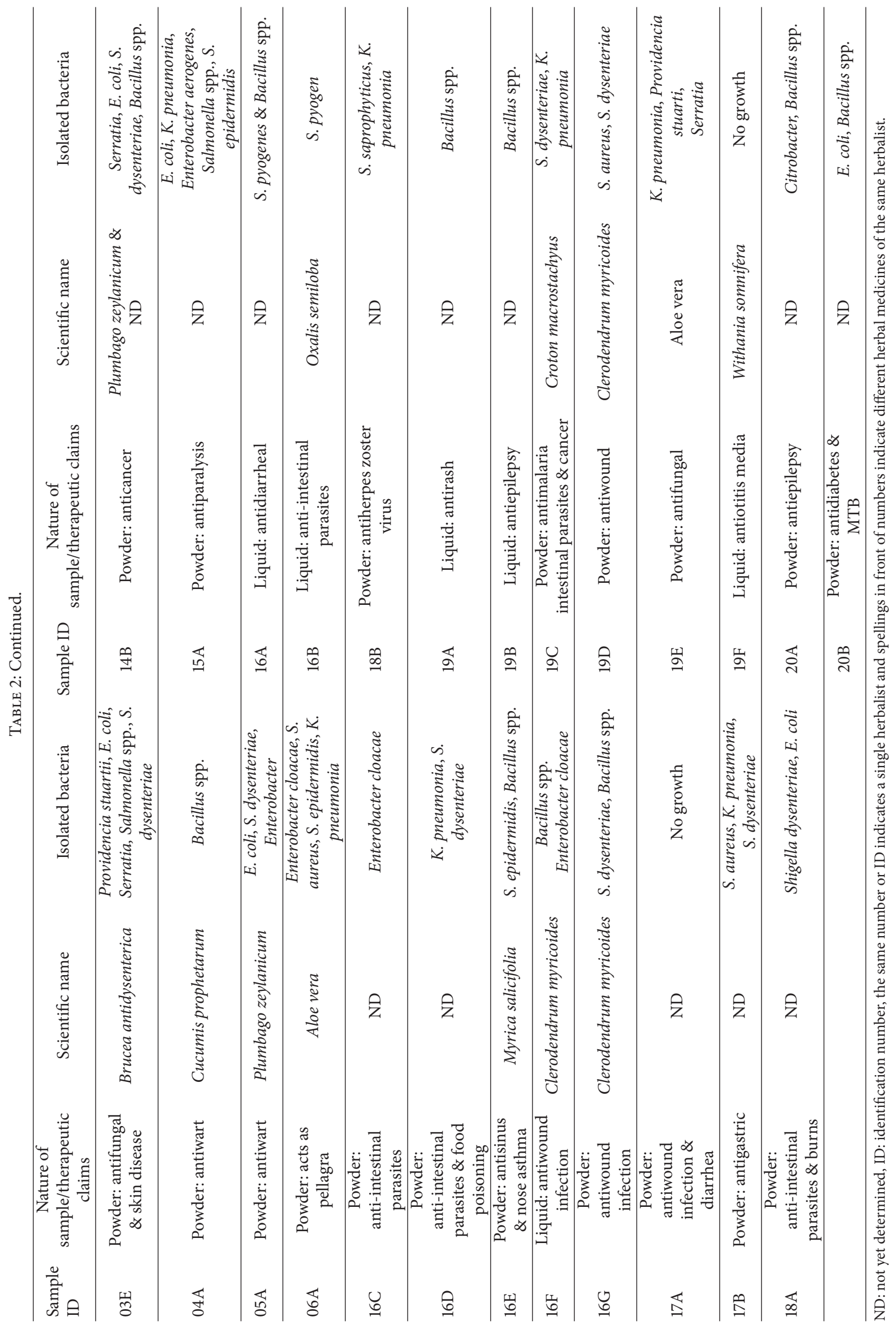


TABLE 3: Bacterial profiles isolated from herbal medicinal products sold in different markets in Gondar Town, Northwest Ethiopia, from April 1 to May 25, 2013.

\begin{tabular}{lc}
\hline Bacterial isolates & Frequency N (\%) \\
\hline Gram negatives & \\
Enterobacter cloacae & $18(12)$ \\
Enterobacter aerogenes & $4(2.7)$ \\
Shigella dysenteriae & $13(8.7)$ \\
Klebsiella pneumoniae & $11(7.3)$ \\
Klebsiella ozaenae & $4(1.7)$ \\
Escherichia coli & $10(6.7)$ \\
Providencia spp. & $12(8.0)$ \\
Citrobacter spp. & $12(8.0)$ \\
Serratia spp. & $5(3.3)$ \\
Acinetobacter spp. & $4(2.7)$ \\
Salmonella spp. & $3(2.0)$ \\
Pseudomonas aeruginosa & $2(1.3)$ \\
Gram positives & \\
Bacillus spp. & $31(20.7)$ \\
Staphylococcus aureus & $10(6.7)$ \\
Staphylococcus epidermidis & $5(3.3)$ \\
Staphylococcus saprophyticus & $2(1.3)$ \\
Streptococcus pyogenes & $4(2.7)$ \\
\hline Total & $150(100 \%)$ \\
\hline
\end{tabular}

In the present study, a positive coliform count was obtained from 37 samples with a minimum count of $1.9 \times$ $10^{4} \mathrm{CFU} / \mathrm{g}$ and maximum count of $2.1 \times 10^{9} \mathrm{CFU} / \mathrm{g}$ with a mean count of $1.56 \times 10^{8} \mathrm{CFU} / \mathrm{g}$ or $\mathrm{mL}$. All of the positive coliform counts were values above WHO tolerable limit [20]. In a study conducted by Khattak in Peshawar City, Pakistan, the coliform bacteria were detected and the counts ranged from $1.5 \times 10^{2} \mathrm{CFU} / g$ to $1.6 \times 10^{4} \mathrm{CFU} / \mathrm{g}$ [8]. This high coliform count in the present study may be due to unhygienic practice and most of the herbalists work with their living house which may increase human drug contact.

Among the total 55 samples $23(41.8 \%)$ and from the positive total coliform bacteria count samples 23 (62.2\%) show fecal indicator organisms like Escherichia coli, Salmonella, Shigella, Staphylococcus aureus, or Pseudomonas aeruginosa [7, 9]. Similar studies conducted in Nigeria and Kaduna Metropolis by Esimone et al. [9] and by Danladi et al. [7] showed the presence of fecal indicators organisms in herbs due to unsafe collection, transportation, drying, preparing, storing, and dispensing processes.

The present study showed bacterial isolates like Bacillus, Citrobacter, Clostridium, Enterobacter, Escherichia, Klebsiella, Pseudomonas, Salmonella, Shigella, Staphylococcus, Serratia, and Streptococcus. This report was similar to reports in Nigeria [12, 23, 25-27]. The finding of coliforms like Escherichia coli, Salmonella spp., and Shigella dysentery is very important public health concern that needs urgent need of management of herbal medicinal products to insure their safety and quality issue.

Multiple drug resistance was common in the present study; it was found that $131(87.3 \%)$ of the isolates were resistant to ampicillin, $95(63.3 \%)$ resistant to amoxicillin clavulanic acid (augmentin), 92 (61.3\%) to amoxicillin, and $30(57.7 \%)$ to penicillin. Adeleye et al., from Nigeria [24], reported that most of the isolates were resistant to ampicillin, penicillin, cotrimoxazole, and gentamicin. A study conducted in Saudi Arabia showed that bacterial isolates of Shigella spp., Enterobacter spp., Escherichia coli, Staphylococcus spp., and Klebsiella spp. were sensitive to amoxicillin and gentamicin [9]. But the present study showed high level of resistance to amoxicillin. This may be due to the overprescription of amoxicillin in our setup which may act as selective pressure for the growth of amoxicillin resistant strains by suppressing the sensitive strains.

\section{Conclusion and Recommendation}

The present study showed that herbal medicinal preparations sold in the study area were highly contaminated with pathogenic microorganisms with very high microbial load. More than $40 \%$ of the samples contain fecal indicator organisms. Multiple drug resistance was not uncommon and it was found that $125(83.3 \%)$ of the isolates were resistant to 2 or more antibiotics tested.

Using those contaminated herbal medicines may have very high health risk due to their biological hazard. This warrants urgent need of management of herbalists or herbal medicinal products to scale up its quality and safety issue. Furthermore, establishing a quality and safety diagnostic service and competency certificate for safe drugs may provide quality and safety initiation between herbalists and good information for the customers.

\section{Competing Interests}

The authors declare that they have no competing interests.

\section{Authors' Contributions}

Abdela Yesuf has contributed to conception and designing of the research idea, proposal writing, data collection and analysis, and paper writing. Yitayih Wondimeneh has participated in the design of the study, analysis and interpretations of the findings, drafting the paper, and writing up. Teklay Gebrecherkos is working with the PI during data collection and laboratory work, data analysis, and paper writing. Feleke Moges has contributed to conception and designing of the research idea, proposal writing, data analysis, and paper writing. All authors are involved in reviewing the paper and approval for publication.

\section{Acknowledgments}

The authors are very thankful to all the herbalists who voluntarily support this study. 
อิ

$\stackrel{2}{\circ}$

起

हี

$\because 0$

흄굴

声文

这

苞

z 을

ही

范

홀

号

घ है

궁

चี

过

寻.

窇

อี้

콜

뭉

逑

글

过

苋

20

윰

㥼

के

者

Е

苋

क्ष

릉

氧

番

을

है

韋

离需

अं.

药

岕晃

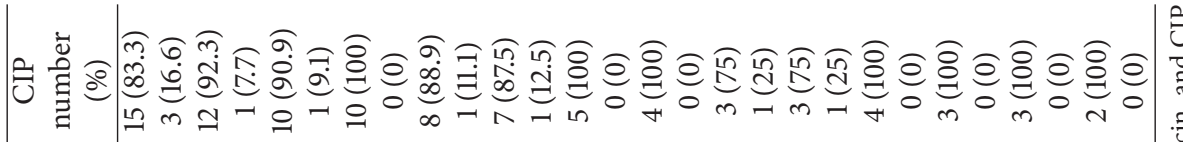

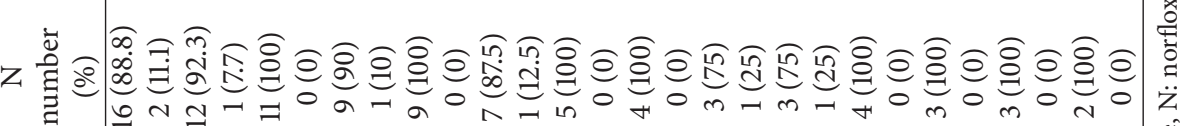

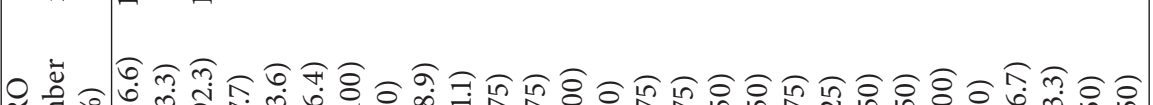

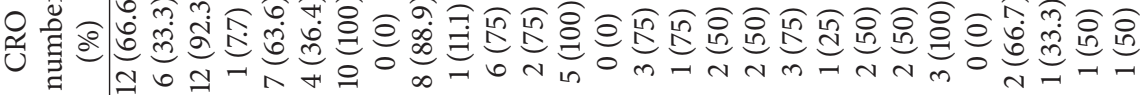

u

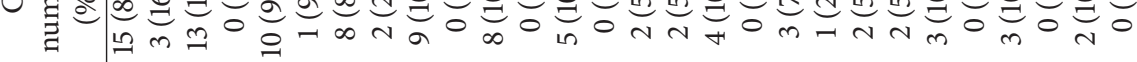

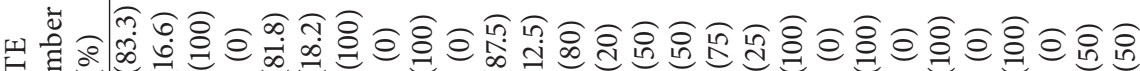

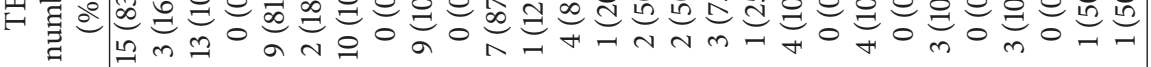

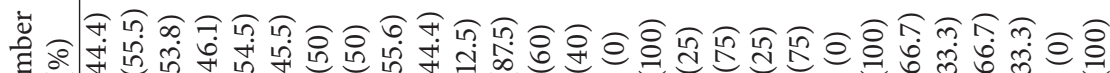

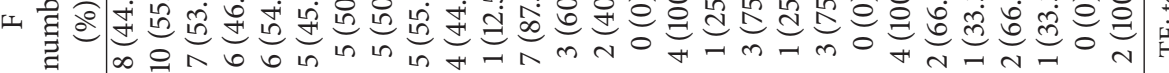

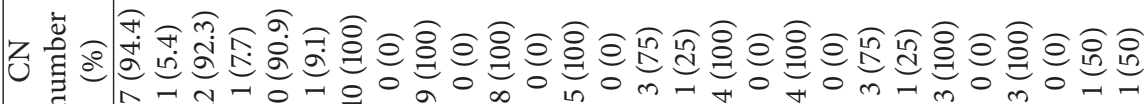

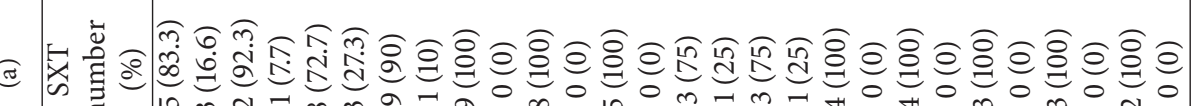

U

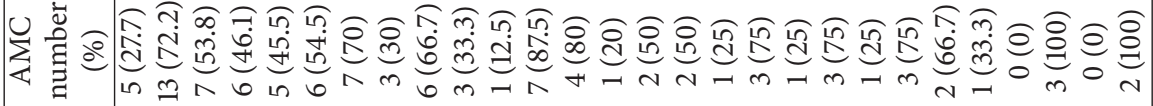

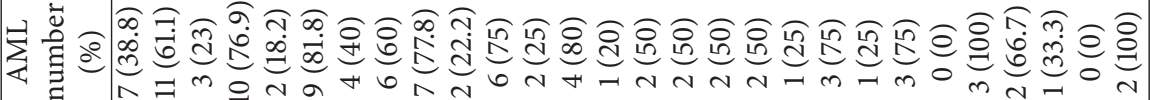

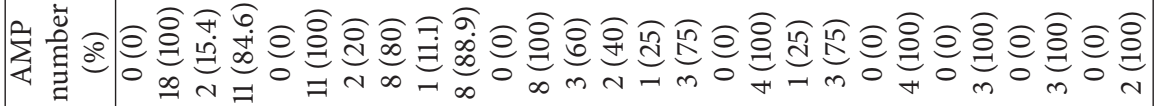

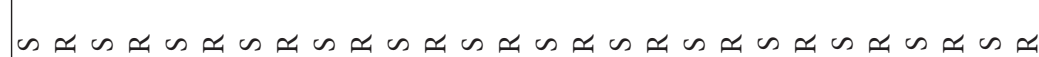

政

$\ddot{\bar{\nu}}$

䒠

严

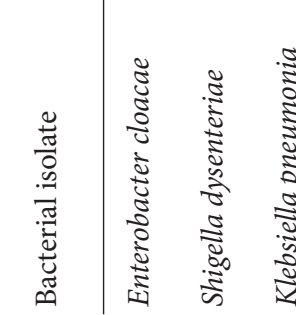

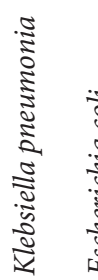

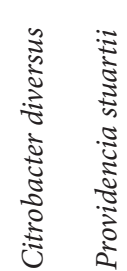

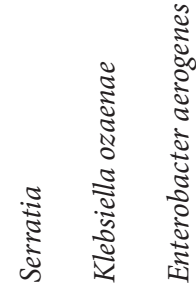

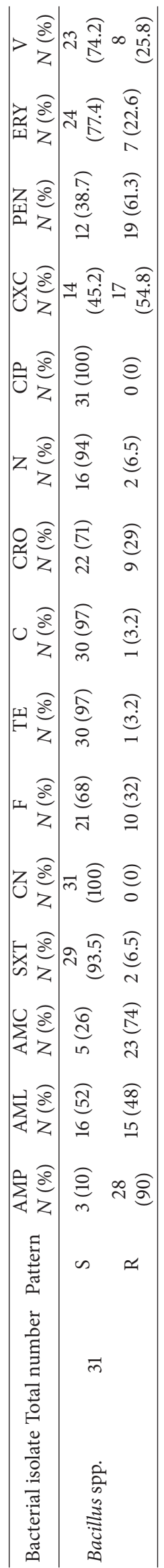




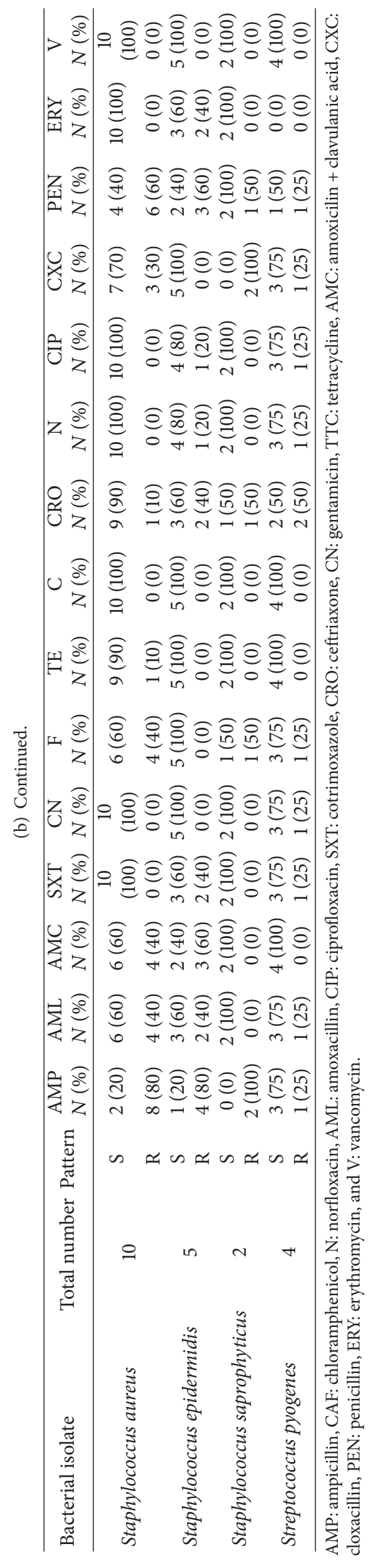


TABlE 5: Drug resistant patterns of bacterial isolates identified from herbal medicinal products in Gondar, Northwest Ethiopia, from April 1 to May 25, 2013.

\begin{tabular}{lccc}
\hline List of antibiotics & $\begin{array}{c}\text { Rate of resistance among gram } \\
\text { negatives } \\
N=98(\%)\end{array}$ & $\begin{array}{c}\text { Rate of resistance among gram } \\
\text { positives } \\
N=52(\%)\end{array}$ & $5=150(\%)$ \\
\hline Cotrimoxazole & $10(10.2)$ & $5(9.6)$ & $15(10 \%)$ \\
Gentamycin & $6(6.1)$ & $2(3.9)$ & $7(4.7 \%)$ \\
Tetracycline & $11(11.2)$ & $16(30.8)$ & $13(8.7 \%)$ \\
Nitrofurantoin & $57(58.2)$ & $30(42.3)$ & $73(48.7 \%)$ \\
Amoxicillin clavulanic acid & $65(63.3)$ & $16(30.8)$ & $37(63.3 \%)$ \\
Ceftriaxone & $22(22.4)$ & $43(82.7)$ & $38(25.4 \%)$ \\
Ampicillin & $88(89.8)$ & $34(65.4)$ & $131(87.3 \%)$ \\
Amoxicillin & $58(59.8)$ & $1(1.9)$ & $92(61.3 \%)$ \\
Chloramphenicol & $11(11.2)$ & $4(7.6)$ & $12(8 \%)$ \\
Norfloxacin & $7(7.1)$ & $2(3.8)$ & $11(7.3 \%)$ \\
Ciprofloxacin & $9(9.2)$ & $23(44.2)$ & $11(7.3 \%)$ \\
Cloxacillin & - & $30(57.7)$ & $23(15.3 \%)$ \\
Penicillin & - & $9(17.3)$ & $30(20.0 \%)$ \\
Erythromycin & - & $8(15.4)$ & $9(6.0 \%)$ \\
Vancomycin & - & $8(5.3 \%)$ & \\
\hline & & \\
\end{tabular}

TABLE 6: Multidrug resistance patterns of bacterial isolates from herbal medicinal products sold in Gondar Town, Northwest Ethiopia, 2013.

\begin{tabular}{|c|c|c|c|c|c|c|c|}
\hline \multirow{2}{*}{ Bacterial isolates } & \multirow{2}{*}{ Total (\%) } & \multicolumn{6}{|c|}{ Number of antibiotics resistance patterns $N(\%)$} \\
\hline & & R0 & $R 1$ & $R 2$ & R3 & $R 4$ & $\geq R 5$ \\
\hline Gram negatives & $98(65.3)$ & $7(7.1)$ & $9(9.2)$ & $19(19.4)$ & $22(22.5)$ & $19(19.4)$ & $22(22.4)$ \\
\hline Enterobacter cloacae & $18(18.4)$ & $0(0)$ & $0(0)$ & $4(22.2)$ & $5(27.7)$ & $5(27.7)$ & $4(22.2)$ \\
\hline Enterobacter aerogenes & $4(4)$ & $0(0)$ & $0(0)$ & $0(0)$ & $2(50)$ & $1(25)$ & $1(25)$ \\
\hline Shigella dysenteriae & $13(13.3)$ & $2(15.4)$ & $1(7.7)$ & $2(15.4)$ & $2(15.4)$ & $5(38.5)$ & $1(7.7)$ \\
\hline Klebsiella pneumonia & $11(11.2)$ & $0(0)$ & $1(9.1)$ & $3(27.3)$ & $3(27.3)$ & $0(0)$ & $4(36.4)$ \\
\hline Klebsiella ozaenae & $4(4)$ & $0(0)$ & $1(25)$ & $1(25)$ & $0(0)$ & $0(0)$ & $2(50)$ \\
\hline Escherichia coli & $10(10.2)$ & $2(20)$ & $1(10)$ & $3(30)$ & $1(10)$ & $1(10)$ & $2(20)$ \\
\hline Providencia stuartii & $12(12.2)$ & $1(8.3)$ & $0(0)$ & $1(8.3)$ & $3(25)$ & $4(33.3)$ & $3(25)$ \\
\hline Citrobacter spp. & $12(12.2)$ & $1(8.3)$ & $3(25)$ & $2(16.7)$ & $2(16.7)$ & $3(25)$ & $0(0)$ \\
\hline Serratia & $5(5.1)$ & $1(20)$ & $2(40)$ & $1(20)$ & $1(20)$ & $0(0)$ & $0(0)$ \\
\hline Salmonella spp. & $3(3)$ & $0(0)$ & $0(0)$ & $1(33.3)$ & $2(66.7)$ & $0(0)$ & $0(0)$ \\
\hline Pseudomonas aeruginosa & $2(2)$ & $0(0)$ & $0(0)$ & $0(0)$ & $0(0)$ & $0(0)$ & $2(100)$ \\
\hline Acinetobacter & $4(4)$ & $0(0)$ & $0(0)$ & $0(0)$ & $1(25)$ & $0(0)$ & $3(75)$ \\
\hline Gram positives & $52(34.7)$ & $7(13.5)$ & $2(3.8)$ & $4(7.7)$ & $12(23.1)$ & $9(17.3)$ & $18(34.6)$ \\
\hline Bacillus spp. & $31(59.6)$ & $4(12.9)$ & $1(3.2)$ & $4(12.9)$ & $4(12.9)$ & $7(22.6)$ & $11(35.5)$ \\
\hline Staphylococcus aureus & $10(19.2)$ & $1(10)$ & $0(0)$ & $0(0)$ & $5(50)$ & $1(10)$ & $3(30)$ \\
\hline Staphylococcus epidermidis & $5(9.6)$ & $1(20)$ & $0(0)$ & $0(0)$ & $2(40)$ & $0(0)$ & $2(40)$ \\
\hline Staphylococcus saprophyticus & $2(3.8)$ & $0(0)$ & $1(50)$ & $0(0)$ & $0(0)$ & $1(50)$ & $0(0)$ \\
\hline Streptococcus pyogenes & $4(7.7)$ & $1(25)$ & $0(0)$ & $0(0)$ & $1(25)$ & $0(0)$ & $2(50)$ \\
\hline Total MDR (G- and $G+)$ & $150(100)$ & $14(9.3)$ & $11(7.3)$ & $23(15.3)$ & $34(22.7)$ & $28(18.7)$ & $40(26.7)$ \\
\hline
\end{tabular}

MDR: multiple drug resistance (resistant to 2 or more antibiotics), $R 0$ : no antibiotic resistance, $R 1$ : resistance to one, $R 2$ : resistance to two, $R 3$ : resistance to three, $R 4$ : resistance to four, and $\geq R 5$ : resistance to five and more drugs. 


\section{References}

[1] N. S. Olisa and F. T. Oyelola, "Evaluation of use of herbal medicines among ambulatory hypertensive patients attending a secondary health care facility in Nigeria," International Journal of Pharmacy Practice, vol. 17, no. 2, pp. 101-105, 2009.

[2] I. A. Oreagba, K. A. Oshikoya, and M. Amachree, "Herbal medicine use among urban residents in Lagos, Nigeria," BMC Complementary and Alternative Medicine, vol. 11, article 117, 2011.

[3] S. Tiwari, "Plants: a rich source of herbal medicine," Journal of Natural Products, vol. 1, pp. 27-35, 2008.

[4] World Health Organization, Traditional Medicine Strategy 2002-2005, WHO, Geneva, Switzerland, 2002.

[5] World Health Organization, WHO Guidelines for Assessing Quality of Herbal Medicines with Reference to Contaminants and Residues, WHO Press, Geneva, Switzerland, 2007.

[6] I. Kosalec, J. Cvek, and S. Tomic, "Contaminants of medicinal herbs and herbal products," Archives of Industrial Hygiene and Toxicology, vol. 60, no. 4, pp. 485-501, 2009.

[7] A. Danladi, I. Inabo, E. Yakubu, and S. Olonitola, "Contamination of herbal medicinal products marketed in Kaduna metropolis with selected pathogenic bacteria," African Journal of Traditional, Complementary and Alternative Medicines, vol. 6, no. 1, pp. 70-77, 2009.

[8] F. Khattak, "3 Microbiological quality assessment of commercially available medicinal plants in peshawar city, Pakistan," Pakistan Journal of Botany, vol. 44, no. 4, pp. 1203-1208, 2012.

[9] C. O. Esimone, P. O. Oleghe, E. C. Ibezim, C. O. Okeh, and I. R. Iroha, "Susceptibility-resistance profile of micro-organisms isolated from herbal medicine products sold in Nigeria," African Journal of Biotechnology, vol. 6, no. 24, pp. 2766-2775, 2007.

[10] J. Oluyege and D. Adelabu, "Microbial contamination of some hawked herbal products in Ado-Ekiti, Nigeria," Continental Journal of Microbiology, vol. 4, pp. 8-14, 2010.

[11] D. Kebede, A. Alemayehu, G. Binyam, and M. Yunis, "A historical overview of traditional medicine practices and policy in Ethiopia," Ethiopian Journal of Health Development, vol. 20, no. 2, pp. 127-134, 2006.

[12] M. Bishaw, "Promoting traditional medicine in Ethiopia: a brief historical review of government policy," Social Science and Medicine, vol. 33, no. 2, pp. 193-200, 1991.

[13] D. Belayineh, D. Eskindir, A. Fikir, and A. Asrat, "Traditional medicine practices in northeast Ethiopia," International Journal of Traditional and Natural Medicines, vol. 1, no. 2, pp. 64-74, 2012.

[14] J. Mittell, "Wikis and participatory fandom," in The Participatory Cultures Handbook, pp. 35-42, 2013, 2013.

[15] S. Tatjana, P. Snežana, S. Stanković, and Š. Katarina, "Pathogenic microorganisms of medicinal herbal drugs," Archives of Biological Sciences, vol. 64, no. 1, pp. 49-58, 2012.

[16] C. O. Esimone, K. F. Chah, and S. C. Ikejide, "Microbiological quality of herbal preparations marketed in south east Nigeria," Journal of Natural Remedies, vol. 2, no. 1, pp. 42-48, 2002.

[17] M. Idu, O. Erhabor, and O. Idele, "Microbial load of some medicinal plants sold in local markets of Benin City, Nigeria," International Journal of Medicinal and Aromatic Plants, vol. 1, no. 3, pp. 272-277, 2011.

[18] P. Omoikhudu, D. Chukwu, and U. Ema, "Multi-drug-resistant bacteria isolates recovered from herbal medicinal preparations in a southern Nigerian setting," Journal of Rural and Tropical Public Health, vol. 10, no. 11, pp. 70-75, 2011.
[19] J. Pelczar, C. Bard, and W. Burnett, Manual of Microbiological Methods, The Society of American Bacteriologists, New York, NY, USA, 1957.

[20] P. Patel, N. Patel, and P. Patel, "WHO guidelines on quality control of herbal medicines," International Journal of Research in Ayurveda and Pharmacy, vol. 2, no. 4, pp. 1148-1154, 2011.

[21] W. R. Bailay and E. S. Scott, Diagnostic Microbiology, Mosby, St. Louis, Mo, USA, 4th edition, 1994.

[22] A. Wikler, R. Cockerill, A. Craig et al., "Performance standards for biochemical testing,seventeenth informational supplement," CLSI, vol. 26, no. 3, pp. 1-177, 2007.

[23] A. A. O. Ogunshe and T. T. Kolajo, "In vitro phenotypic antibiotic resistance in bacterial flora of some indigenous orally consumed herbal medications in Nigeria," Journal of Rural and Tropical Public Health, vol. 5, pp. 9-15, 2006.

[24] I. A. Adeleye, G. Okogi, and E. O. Ojo, "Microbial contamination of herbal preparations in Lagos, Nigeria," Journal of Health, Population and Nutrition, vol. 23, no. 3, pp. 296-297, 2005.

[25] A. Ogunshe, R. Fasola, and A. Egunyomi, "Bacterial profiles and consumer preference of some indigenous orally consumed herbal medications in Nigeria," Journal of Rural and Tropical Public Health, vol. 5, pp. 27-33, 2006.

[26] A. Ogunshe and T. Kolajo, "In vitro phenotypic antibiotic resistance in bacterial flora of some indigenous orally consumed herbal medications in Nigeria," Journal of Rural and Tropical Public Health, vol. 5, pp. 9-15, 2006.

[27] S. S. Alwakeel, "Microbial and heavy metals contamination of herbal medicines," Research Journal of Microbiology, vol. 3, no. 12, pp. 683-691, 2008. 

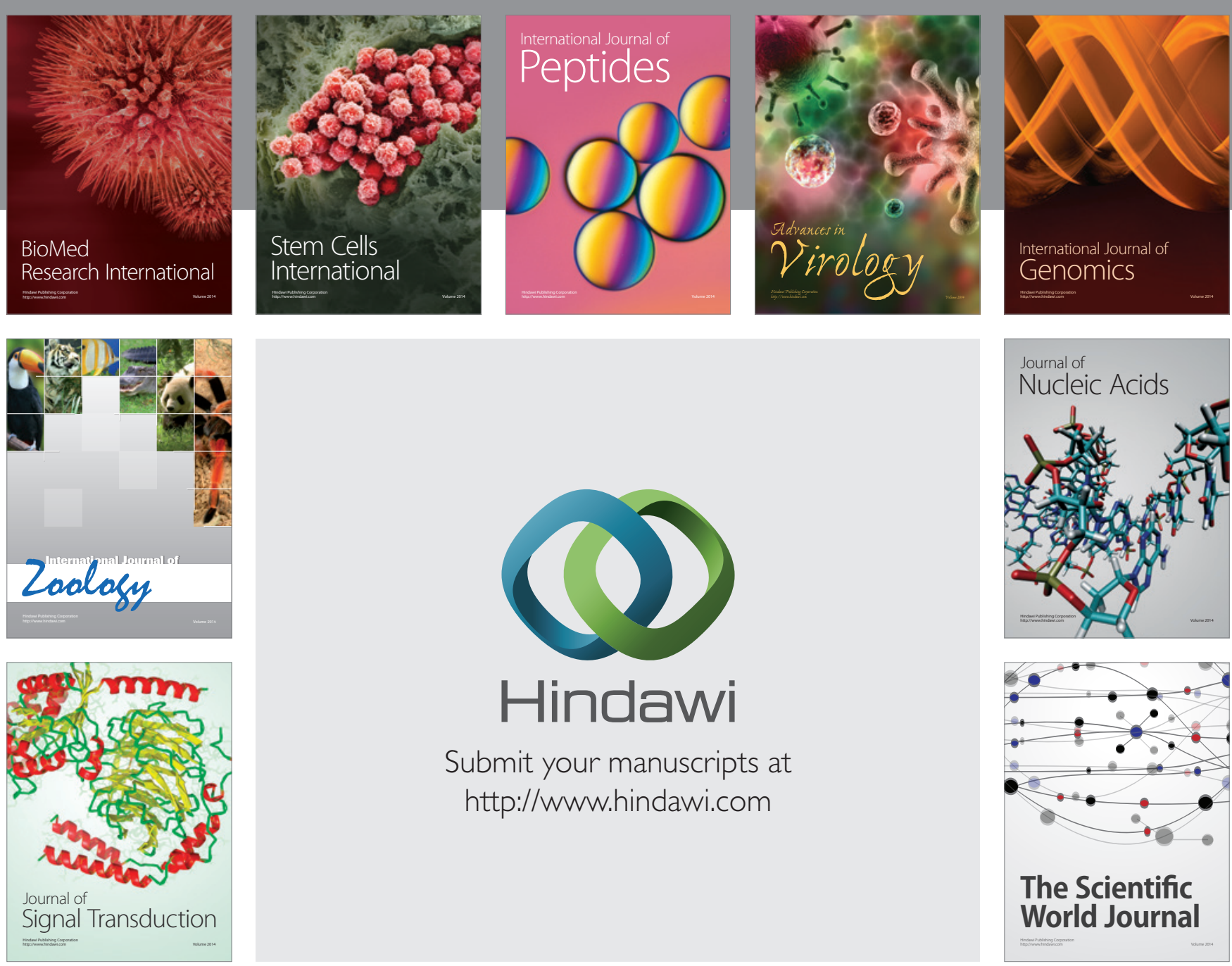

Submit your manuscripts at

http://www.hindawi.com
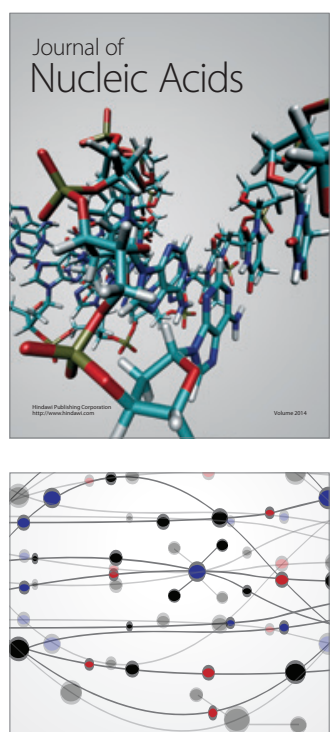

The Scientific World Journal
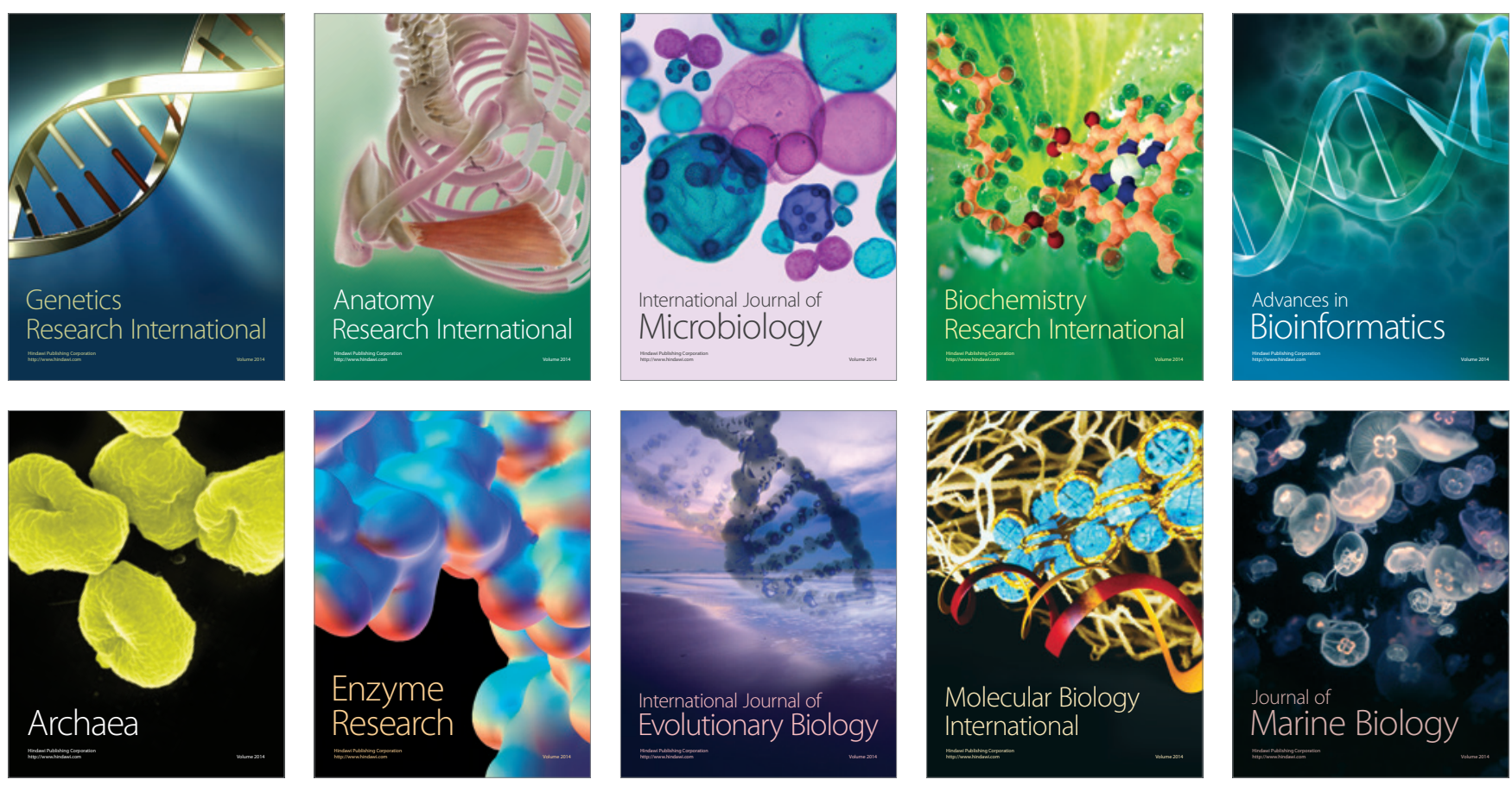